\title{
Sensitivity of urban water resources in Phoenix, Tucson, and Sierra Vista, Arizona, to severe drought
}

\author{
Barbara J. Morehouse*, Rebecca H. Carter, Petra Tschakert
}

Institute for the Study of Planet Earth, The University of Arizona, 715 N. Park, 2nd Floor, Tucson, Arizona 85721, USA

\begin{abstract}
Water scarcity is an ever-present fact of life in the arid and increasingly urbanized Southwest. Yet even with the considerable effort expended on drought-proofing urban areas through infrastructure and policy development, droughts of magnitudes found in the historical records of the past 100 yr continue to threaten the region's cities. Results of an analysis of the sensitivity of 3 urban areas in Arizona to selected drought scenarios suggest that severe droughts of 1,5, and 10 yr duration would severely stress existing water supply/demand budgets. The results of the analysis suggest that very considerable conservation efforts would be required to bring demand into balance with existing supply. This article reports on the results of analysis of the sensitivity of urban water systems in the Phoenix and Tucson metropolitan areas as well as in the Sierra Vista subwatershed, which includes the rapidly growing city of Sierra Vista and the adjacent Fort Huachuca Army Base.
\end{abstract}

KEY WORDS: Urban water $\cdot$ Climate impacts

\section{INTRODUCTION}

Building on $100 \mathrm{yr}$ of engineering and $20 \mathrm{yr}$ of innovative water policy development, Arizona cities have overcome many of the constraints posed by the region's semiarid climate-particularly drought. Yet considerable potential still exists for extreme stress arising from extended and severe drought conditions. Examination of some $100 \mathrm{yr}$ of climate data and historical information for Arizona indicates that deep droughts have occurred in the not-too-distant past, and that these droughts have wrought substantial havoc on the area's human and natural systems. Activities such as construction of the Central Arizona Project (CAP) (Fig. 1) have provided a good buffer against a normally wide variation in climatic conditions at seasonal, annual, and interannual timeframes, but remain untested against a major drought. This paper begins with a summary of the analytical approach used, discussion of how the study areas were selected, and the

*E-mail: morehoub@u.arizona.edu variables used in the spreadsheet model. A brief background of water structures and institutions in Arizona is then provided, followed by a review of relevant literature. The article then summarizes the results of an analysis conducted to determine the sensitivity of urban water supplies in selected Arizona urban areas to severe drought and examines some of the implications.

\section{STUDY DESIGN}

We designed our urban water sensitivity analysis around the Intergovernmental Panel on Climate Change (IPCC) definition of sensitivity as 'the degree to which a system will respond to a change in climatic conditions, for example the extent of change in ecosystem composition, resulting from a given change in precipitation or temperature' (1996, p. 5). Thus, we sought to identify the degree to which water availability would change based on selected reductions in precipitation over a 1, 5, and $10 \mathrm{yr}$ period. The droughts 


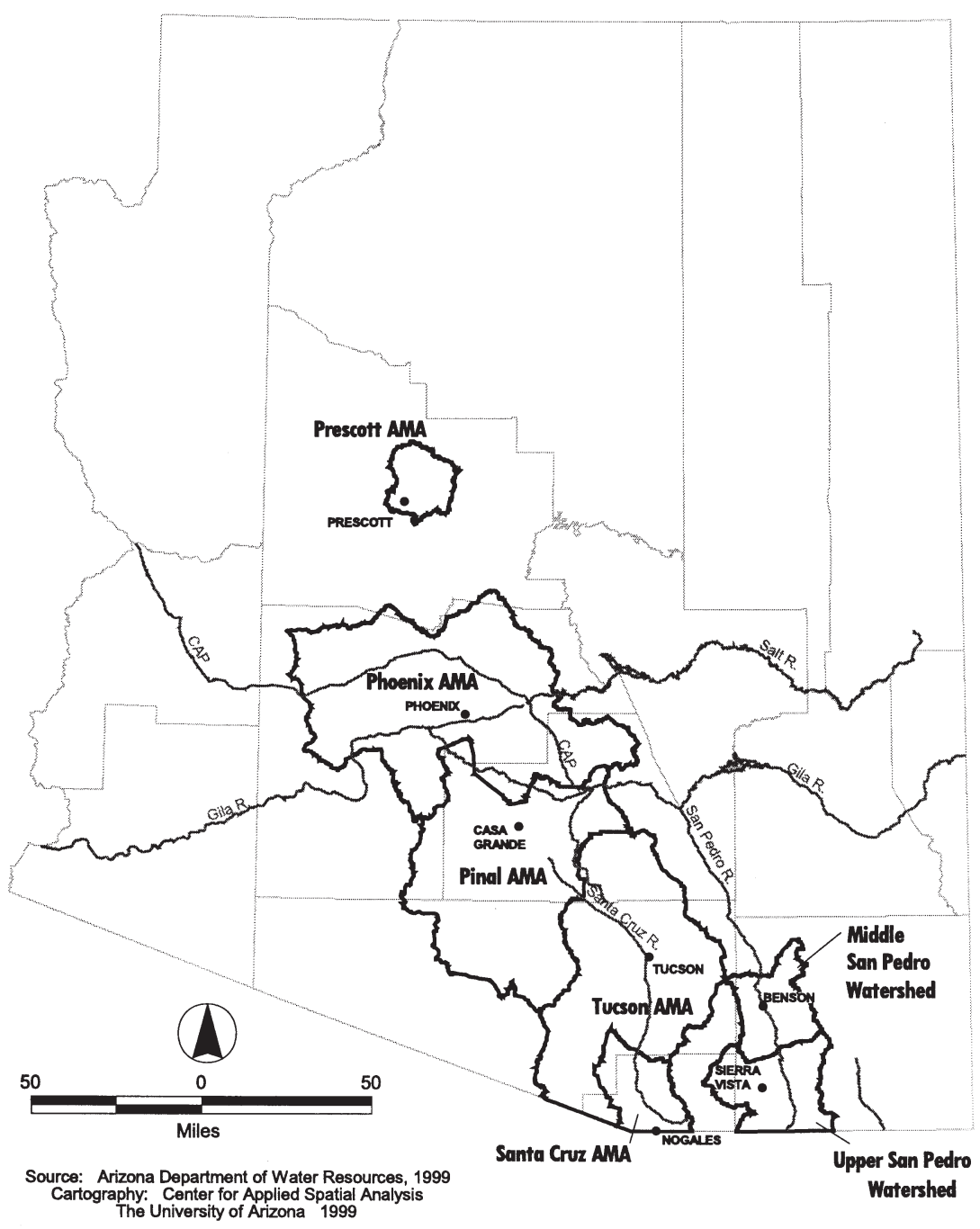

Fig. 1. Study areas in Arizona. CAP: Central Arizona Project. AMA: Active Management Area

the extent of basic sensitivity of the water supply to climate, we did not deem this lag to be critical to the fundamental question at hand.

We opted to use winter (November to April) precipitation in 4 of the 5 study areas based on research that indicates that it is generally winter precipitation that contributes the greatest amount to surface flow and groundwater recharge in those areas. Thus, according to Sheppard et al. (1999), while up to $60 \%$ of the southwest's annual rainfall comes during the summer monsoon season, under typical climate conditions, little, if any, of this amount reaches the aquifer or is stored in reservoirs for later use. For the fifth study area, the Santa Cruz Active Management Area (AMA) on the southern border of Arizona, we used annual precipitation numbers, because a large portion of the water supplies in this area are shallow - and thus readily depleted-and at the same time are highly responsive to precipitation events (ADWR 1999c).

All together, we analyzed 5 areas: the Phoenix, Tucson, and Santa Cruz AMAs, which are administered by the Arizona Department of Water Resources (ADWR), and the Sierra Vista and Benson subwatersheds of the San Pedro River (see Fig. 1). Four of the study areas (the Tucson AMA, the Santa Cruz AMA, the Benson subwatershed, and the Sierra Vista subwatershed) are located in southeastern Ari-

selected for use in the study were the most severe deficits documented in the historical record for the climate division within which the study area was located. The basic spreadsheet calculations involved reducing renewable water supplies by the proportional decrease in winter precipitation. We assumed that the drought would extend across the summer season, as occurred in the historical record.

For the Phoenix and Tucson areas, both of which rely on CAP water from the Colorado River, we developed worst-case 5 and 10 yr scenarios that assumed a basinwide drought on the Colorado, and thus zero delivery of CAP water throughout the period of the drought scenario. We recognized that there would be a lag time between the onset of reduced precipitation and any reduction in Colorado River allocations; however, because the purpose of the analysis was to determine zona, while the Phoenix AMA is in the central part of the state. The Phoenix and Tucson AMAs were chosen because they include the 2 largest cities in the state, and because both are growing rapidly in a context of potentially limited water supply. The Santa Cruz AMA was chosen because it is located on the US-Mexico border and thus incorporates important international water issues; the community also presents several interesting contrasts to the water supply and demand contexts of the Phoenix and Tucson AMAs.

Sierra Vista, the only large urban area in the Sierra Vista subwatershed, is a rapidly growing city located adjacent to the US Army's Fort Huachuca military base. Both are located near the San Pedro River. This river has been identified as one of the most important riparian areas in the United States (American Rivers 1999; '10 most endangered rivers: the Upper 
San Pedro.' www.americanrivers.org/pressrelease/ pressmersanpedro1999.htm), and both the community and the base are currently under pressure to consider the impacts of their groundwater pumping on the viability of the riparian ecosystem. The area uses large amounts of groundwater yet is not subject to the level of stringent regulation imposed on the 3 AMAs discussed above. Climate variability, when added to the pressures of existing and anticipated urban activity and ecosystem needs, has the potential to significantly intensify existing pressures.

The town of Benson constitutes the major population center in the middle San Pedro River, downstream from Sierra Vista and the protected riparian area along the San Pedro River. With a total population throughout the entire watershed of only about 6000 people, the area does not qualify as significantly urban. However the area was the focus of community case study of climate vulnerability and thus provides insight into how climate might affect water resources in the context of a small community undergoing rapid development arising from tourism and increases in winter residents.

We developed a series of scenarios to test the sensitivity of each area's water system to drought. A summary of the major scenarios we analyzed for the Phoenix and Tucson AMAs is provided below; for a complete discussion of the methodology used, see Carter et al. (2000). See Fig. 2 for an example of the spreadsheet format used in the analysis.

\section{One-year drought:}

- Baseline supply and demand conditions as of 1995 (the most recent year for which consistent data are available); assumes no drought

- Baseline supply and demand conditions for the year 2025 (the year the Arizona Groundwater Management Act [GWMA] specifies that the AMAs should be at safe yield-discussed later in this paper); assumes no drought

- 1 yr drought calculated against supply and demand conditions for 2025; in addition to decreasing supplies by the percentage reduction in precipitation, demand was increased to account for assumed higher water use, particularly for outdoor watering, during the drought period

- Reduced supply due to drought, and demand based on (higher) 1995 agricultural usage

- 1 yr drought and 2025-level demand, but with agricultural use reduced to zero

Five- and ten-year droughts:

- Baseline 5 and 10 yr supply and demand levels for 1995 and 2025

- 5 and 10 yr droughts, calculated as percentage of renewable supply relative to baseline 5 and $10 \mathrm{yr}$ supply and demand conditions, respectively, for 2025

- Same as above, but eliminating CAP supplies (Phoenix and Tucson only; CAP water is not available in Sierra Vista)

\begin{tabular}{|c|c|c|c|c|c|c|c|c|c|}
\hline & $\begin{array}{c}\text { Baseline } \\
1995 \\
\text { x } 5 \text { yrs }\end{array}$ & $\begin{array}{c}\text { Baseline } \\
1995 \times 5 \\
\text { yrs, w/5-yr } \\
\text { drought }\end{array}$ & $\begin{array}{c}\text { TMP* } \\
2025 \\
\text { Baseline } \\
\text { x } 5 \text { yrs }\end{array}$ & $\begin{array}{c}2025 \times 5 \\
\text { yrs }+ \\
5-y r . \\
\text { drought }\end{array}$ & $\begin{array}{c}2025 \mathrm{x} \\
5 \mathrm{yrs}+5- \\
\mathrm{yr} \\
\text { drought, } \\
\text { zero CAP }\end{array}$ & $\begin{array}{c}2025 \mathrm{x} \\
5 \mathrm{yrs} \mathrm{w} / \\
1995 \text { agric } \mathrm{x} \\
5 \mathrm{yrs}+5-\mathrm{yr} \\
\text { drought }\end{array}$ & $\begin{array}{c}2025 \times 5 \text { yrs } \\
\text { w/1995 } \\
\text { agric x } 5 \text { yrs } \\
+5-y r \\
\text { drought, } \\
\text { zero CAP }\end{array}$ & $\begin{array}{c}2025 \mathrm{x} \\
5 \mathrm{yrs} \\
\text { w/ zero } \\
\text { agric, } 5-\mathrm{yr} \\
\text { drought }\end{array}$ & $\begin{array}{c}2025 \mathrm{x} \\
5 \mathrm{yrs} \text { w/ 5- } \\
\text { yr drought, } \\
\text { zero agric, } \\
\text { zero CAP }\end{array}$ \\
\hline \multicolumn{10}{|l|}{ Renewable Supply } \\
\hline \multicolumn{10}{|l|}{ Total surface water } \\
\hline \multicolumn{10}{|c|}{ Recharge + inflow - outflow } \\
\hline \multicolumn{10}{|l|}{ CAP } \\
\hline \multicolumn{10}{|l|}{ Effluent } \\
\hline \multicolumn{10}{|l|}{ Total renewable supply } \\
\hline \multicolumn{10}{|c|}{ Percentage of 2025 baseline } \\
\hline & & & & & & & & & \\
\hline \multicolumn{10}{|l|}{ Demand } \\
\hline \multicolumn{10}{|l|}{ Municipal } \\
\hline \multicolumn{10}{|l|}{ Agricultural } \\
\hline \multicolumn{10}{|l|}{ Industrial } \\
\hline \multicolumn{10}{|l|}{ Riparian } \\
\hline \multicolumn{10}{|c|}{ Minus incidental recharge } \\
\hline \multicolumn{10}{|c|}{$\begin{array}{l}\text { Minus replenishment } \\
\text { requirement }\end{array}$} \\
\hline \multicolumn{10}{|l|}{ Minus cuts to aquifer } \\
\hline \multicolumn{10}{|l|}{ Total return flow } \\
\hline \multicolumn{10}{|l|}{ Net water consumption } \\
\hline \multicolumn{10}{|c|}{ Percentage of 2025 baseline } \\
\hline & & & & & & & & & \\
\hline \multicolumn{10}{|l|}{ Groundwater Impact } \\
\hline \multicolumn{10}{|l|}{ Renewable supply } \\
\hline \multicolumn{10}{|l|}{ Net consumption } \\
\hline $\begin{array}{l}\text { Percentage met by non- } \\
\text { renewable supplies }\end{array}$ & & & & & & & & & \\
\hline
\end{tabular}

Fig. 2. Sample spreadsheet format 
- Basic 5 and 10 yr drought scenarios, but with agricultural demand at 1995 levels

- Same as above (with agriculture at 1995 levels), but without CAP water (Phoenix and Tucson only)

- Basic 5 and 10 yr drought scenarios, but eliminating all agricultural demand

- Same as above, but eliminating all CAP water eliminated as well (Phoenix and Tucson only)

Note that CAP supplies were not eliminated in the $1 \mathrm{yr}$ drought, on the assumption that sufficient supplies are stored in Lake Powell and Lake Mead, plus through groundwater banking in Arizona, to make up any shortfalls. Also note that no conservation measures or changes in pricing schemes are assumed in these scenarios. The intent was to identify 'worst-case' conditions to facilitate design of effective conservation and water pricing plans, tailored to each area and developed through local and state policy processes. The demand figures used for Sierra Vista assume population growth at a (higher) current rate, rather than the (lower) rate projected by the Arizona Department of Economic Security. Only the results of the scenarios using the $20 \%$ higher rate are reported in this paper, as we deemed the lower rate to be unrealistic, given current trends in that area.

Groundwater overdraft serves as the dependent variable in these scenarios for several reasons, the most important being the high dependency on groundwater in the study areas. Water providers in all the study areas rely on groundwater either as a sole source, a substantial (though partial) source, or an emergency (back-up) source of supply. Given that the Phoenix and Tucson AMAs are mandated to manage their groundwater supplies to achieve sustainability, careful attention to the effects of climate variability on these supplies is essential. To date, assumptions of climate stationarity, or at best variability within a relatively narrow range, have underlain water management policies and procedures in Arizona. By focusing on groundwater impacts, this analysis is intended to stimulate water managers and policy makers to incorporate more detailed and sophisticated climate information and forecasts into their operations.

No assumptions are made regarding the impacts of Indian water rights, although this is a significant issue in both the Tucson and Phoenix AMAs. Indian water is not governed by ADWR through its AMAs. Further, the water-rights settlements reached to date have often carefully differentiated water that is for the tribes alone and that which can be leased or otherwise transferred to non-tribal entities. These kinds of transfers would undoubtedly be pursued by individual providers in the AMAs. However, such potential policy changes were not included in this study. Policy and institutional analyses of climatic impacts on water resources in the Southwest are underway and will address these types of issues.

\section{BACKGROUND}

The completion in 1985 of the CAP represents to developers and politicians achievement of their longsought quest for dependable, renewable water supplies. At the institutional level, the 1980 Arizona GWMA, the enabling act for the ADWR, provides the primary structure for assuring long-term management and conservation of groundwater supplies. It is an important element of water management in Arizona, for groundwater supplies are critical to the well being of urban and rural areas of the state. Specifically, the GWMA seeks to eliminate severe groundwater overdraft in parts of the state where pumping has been seriously depleting groundwater supplies and to provide the institutional structure required to ensure that limited groundwater resources are allocated efficiently to meet water needs (ADWR 1999a).

As originally designed, the CAP canal was intended to deliver dependable surface water flows to the central portion of the state to meet agricultural, industrial, and municipal demands. In reality, even before the first water was delivered to Phoenix in 1985, changes were underway. One of the most important of these changes was the emergence of urban areas as the primary customers of CAP water, rather than agriculture or industry. The agricultural sector largely opted out of the CAP system for economic reasons: it was cheaper to pump groundwater than to contract for CAP water, burdened as it was by high costs for construction, interest, and operations and maintenance. Further, again largely for economic reasons, the CAP canal was never extended to the Prescott AMA nor to providers located south of Tucson. These and other rapidly growing areas of the state are pursuing alternative strategies, such as using effluent for irrigating golf courses and other non-potable uses, to balance their water budgets.

As noted above, while actual or potential water scarcity lay behind these activities, concern about climate impacts has not been a major factor in decisionmaking. Awareness of the implications of climatic variability and longer-term climate change does, however, exist among some urban water managers. A Global Change Symposium, held in Tucson in 1998 (Merideth et al. 1998), sought to identify those areas where the impacts of climatic events and long-term climatic change would be most strongly experienced. Urban water was identified as being one of the sectors likely to be most severely affected by climatic stresses. It was against this backdrop, and in consideration of the fact that water resources remain a source of considerable 
debate across the Southwest, that the Climate Assessment Project for the Southwest (CLIMAS) chose to conduct a sensitivity analysis of selected urban water systems in Arizona.

\section{RELATED STUDIES}

Much of the research into climate impacts on water resources has been directed toward determining the effects of long-term climate change. Although limited ability to downscale the results produced by general circulation models (GCMs) has constrained efforts to identify the impacts of climate change at regional or final scales of resolution, consensus has formed around the notion that arid and semi-arid areas could be among the most seriously affected. Further, relatively small changes in temperature and precipitation, combined with non-linear effects on evapotranspiration processes and soil moisture conditions could result in relatively large changes in runoff-especially in arid and semi-arid regions (IPCC 1995). For example, one study found that a $2^{\circ} \mathrm{C}$ increase in temperature and a $5 \%$ decrease in precipitation would pose challenges to managers of surface water in the Trinity, Colorado, and Rio Grande basins of the United States (Schmandt \& Ward 1993, cited in IPCC 1995). Recognizing the high degree of reliance on groundwater in areas with low surface water availability and dry climates, the IPCC noted that few direct studies of the impacts of global warming on groundwater recharge had been made. Yet 'A shorter recharge season may result from increased temperatures and evaporation in spring and autumn' (1995, p. 336). The implications of such changes for Arizona could be significant, for groundwater provides about half of the water supplies of the state, and the Colorado River now constitutes the largest single source of renewable water supplies for the rapidly growing urban areas in the central portion of the state.

While global warming has been the focus of much of the research pertinent to the CLIMAS urban water study, understanding natural climate variability also holds promise for improving water resource management. Specifically, the IPCC (1995) observed that by focusing on natural climate variability and its implications at regional and local scales, researchers and decision makers may find ways to effectively address, in a context-specific manner, climatically induced imbalances between water supply and demand. Such an approach would also facilitate evaluation of the extent to which water managers can achieve standard performance criteria (reliability, safe yield, probable maximum flood level, resilience and robustness) under different climatic conditions (IPCC 1995).
Even in an age of extensive water engineering, drought remains a significant source of stress to both human and natural systems. To address the problem of drought and its impacts throughout the United States, Congress enacted legislation in 1998 to create a national Drought Commission. The Commission is charged with ensuring development of proactive drought response plans throughout the country. Yet drought eludes easy definition, for any definition must reflect local cultural, social, economic, and physiographic characteristics (IPCC 1995). Further, understanding of the processes producing climate variability -including extended drought conditions - remains incomplete, as does thorough knowledge of the processes by which drought affects human and natural systems.

Frederick (1995) stressed the need to take large seasonal and annual variations into account, and noted that 'the highest levels of use and the lowest prices are often found in the more arid areas of the country' (Frederick 1995, p. 17). He also noted that research on US river basins suggests that safe yield (roughly defined as a balance between maximum withdrawal under specified conditions of inflow and withdrawals) is at a maximum level when the ratio of storage to average annual renewable supply ranges between 1.6 and 4.6. In the arid Southwest, the optimal ratio generally must be at the upper end of this range. Indeed, 'By this criterion, the point of negative returns may already have been reached in 3 major basins - the Lower Colorado, the Upper Colorado, and the Rio Grande...' (Frederick 1995, p. 17).

Drought clearly exacerbates such conditions, and can result in significant social and economic impacts. Although it is very difficult to quantify the socioeconomic impacts of drought, estimates indicate that, in 1991, in the midst of the 1987-1992 drought in California, the agricultural sector experienced $\$ 250$ million in direct losses, less than $2 \%$ of the state's total agricultural revenues (Nash 1993; unclear whether numbers were inflated to constant dollars). However, over the years 1987-1991, urban users in the state saw their water bills rise; many users also were subjected to voluntary or mandatory conservation programs. Electricity costs alone increased to more than $\$ 3$ billion due to reductions in hydroelectric power production (see Gleick \& Nash 1991). These drought conditions were associated with the same La Niña-spawned zonal atmospheric flows that brought very dry conditions to Arizona as well.

Most of the studies pertinent to Arizona that have looked at the impact of climate on water resources have focused on surface water conditions in the Colorado River. For example, Revelle \& Waggoner (1983) found that warmer air temperatures, combined with a 
slight decrease in precipitation, would probably result in a severe reduction in the quantity and quality of Colorado River water. The authors found that, based on multiple regression analysis of mean annual flows at Lees Ferry for the period 1931-1976, 'variations in precipitation were reflected almost linearly in variations in runoff' (p. 431). By contrast, in their analysis of climate change impacts on the Colorado River, Stockton \& Boggess (1979) found that a $2^{\circ} \mathrm{C}$ rise in temperature and a $10 \%$ decrease in precipitation produced a (nonlinear) $44 \%$ decrease in runoff. Nash \& Gleick (1991), using the same temperature and precipitation numbers as Stockton \& Boggess, as well as an $8 \%$ rise in potential evapotranspiration, calculated that a $20 \%$ decrease in runoff would result. In keeping with the findings of Revelle \& Waggoner, but in contrast to the findings of Stockton \& Boggess, they concluded that a linear relationship generally existed between increases or decreases in annual precipitation and increases or decreases in mean annual runoff. Exceptions to linearity only began to occur when precipitation increased by $10 \%$ but temperature and evapotranspiration stayed the same (in which case, runoff also increased). The authors noted, 'Overall, seasonal changes in runoff patterns are likely to be greater than annual changes and may be a more sensitive indicator of climate change' (1991, p. 239).

These findings reveal that uncertainty remains regarding the relationships between precipitation, temperature, runoff, and water supply under conditions of climate variability and change. Based on evaluation of these studies and other factors, and in consultation with our hydrologist colleagues, we determined that the best route in the CLIMAS urban water sensitivity analysis was to assume linearity between precipitation and runoff for all study sites.

The potential for a total cutoff of Arizona's CAP allotment (1.5 maf; million acre feet, or the amount of water required to cover a million acres of ground with 1 foot of water; note that 1 acre $=0.405$ ha; 1 foot $\approx 30.5 \mathrm{~cm}$ ) was an important point of consideration in designing the sensitivity analysis presented here, particularly since Arizona's CAP water right is junior to the other rights in the Lower Colorado Basin. Nash \& Gleick (1993) found that a $10 \%$ decrease in Colorado River flow translated into a 20 to $30 \%$ reduction in storage and power generation and an increase in salinity. Analyzing the best-case scenario of climate change impacts on scheduled water deliveries specified by law and Bureau of Reclamation operating procedures, they found that even a $20 \%$ increase in runoff, combined with warmer temperatures, would translate into Arizona receiving only $97 \%$ of its full CAP allotment. Under the worst-case scenario, the CAP would receive no water at all (Nash \& Gleick 1993). This latter sce- nario was adapted for use in the worst-case scenario developed for the CLIMAS urban water study.

Among the most extensive of these studies was the Severe Sustained Drought project carried out by a multidisciplinary team under the auspices of the Powell Consortium (Powell Consortium 1995). The analysis was based on the most severe drought that could be identified from existing instrumental and tree-ring records. This drought occurred between 1579 and 1598. The $20 \mathrm{yr}$ average flow over these $20 \mathrm{yr}$ was only 10.95 maf, which was 2.55 maf below the 13.5 maf identified as the long-term reconstructed flow of the Colorado River. Should such a reduction occur today, stringent and aggressive measures would be required to achieve equitable apportionment of supplies among the various rights holders, including the CAP and its urban constituents. This sort of impact is reflected in the findings of Harding et al. (1995), who compared the severe sustained drought of the 1500s with a comparably long streamflow record (October 1938 through September 1975) representing normal mean flow conditions. They found that the Upper Basin states of Utah, Wyoming, Colorado, New Mexico, and northern Arizona would be strongly affected by the drought, and that Arizona and Nevada would experience shortages of delivery. Annual water deliveries to the CAP would be reduced to 450000 af, from its regular allotment of 1.5 maf.

Imbalance between renewable supplies and demand continues to challenge water managers in the Southwest. Maddock \& Hines (1995) observed that rapid growth occurred in urban water use between 1965 and 1990. During this time, public supply withdrawals and per capita consumption grew at about double the national rate. This rate of growth accelerated into the early 1990s, although per capita consumption may have begun leveling off in some urban areas.

Although the nation, including the Southwest, is now very predominantly urban, relatively few studies of the impacts of climatic conditions on water resources have focused on urban water systems, particularly with regard to impacts on urban water demand (Boland 1997). Yet warmer, drier weather increases evapotranspiration as well as increased water demand for outdoor irrigation, cooling, and water-oriented recreational activities. Indeed, 'If supply facilities and water management policies continue to be based on an assumption of stationary climate, [warmer and drier] climate... would lead to increased probability and severity of water shortages in the affected urban area' (Boland 1997, p. 158).

Woodard \& Horn (1988) studied the effects of climate on urban water demand in Phoenix and Tucson. They found that demand was more sensitive to climate conditions in Tucson than it was in Phoenix, and that the key variable was decision making on summertime out- 
door irrigation. A comparison of water usage rates with precipitation patterns revealed that Tucson residents were much more likely than Phoenix residents to take amount and timing of rainfall into account when deciding whether or not to water their outdoor vegetation. Phoenix residents were more likely to rely on automated irrigation systems, which operate according to preprogrammed schedules rather than to weather events. Subsequent analysis by the Tucson AMA indicates that summer water use levels closely track evapotranspiration rates (ADWR 1999b).

According to Boland, the impact of climate on water resources 'may be more severe than the magnitude of the climate change alone would suggest' (Boland 1997, p. 158), particularly since current practices associated with forecasting water use assume stationary climate; many assume stationary weather as well (p. 158). The author questions whether 'socially and politically feasible demand management strategies will be sufficient to address [such] climate-induced water shortages' (p. 159). In the United States, factors such as population trends, land use practices, institutional considerations, and values attached to different kinds of water use are seen to influence water resource planning much more strongly than climate (Frederick \& Major 1977; see also Schwarz \& Dillard 1990). Lins \& Stakhiv (1998) questioned the efficacy of sensitivity analyses that have focused on the impact of climate change on water resources. In their view,

'In practice ... water management is a process of continual adaptation using existing or new management options, which is exactly how management has responded to variable climatic conditions during this century. This single weakness renders nearly all of the published studies seriously incomplete and potentially misleading from the standpoint of the consequences for "water resources" (p. 1260).

However, they also noted that,

'Unquestionably, the management of water resources could be significantly enhanced by improving understanding of climatic variability at monthly to seasonal, and interannual to decadal time scales (through such mechanisms as El Niño/Southern Oscillation and Pacific Decadal Oscillation, for example). Better understanding of long-term trends in climate, particularly precipitation, would be of value for infrastructure enhancement and protection' (p. 1264).

\section{Further,}

'... water resources managers must develop their management systems in a context that assumes a wide range of climatic conditions. Plans that assume that future climate will repeat past climate are destined to perform poorly in comparison with plans that recognize the potential for significant and persistent departures from historically 'normal' conditions' (p. 1264).

A recent American Water Resources Association Speciality Conference on the 'Potential Consequences of Climate Variability and Change to Water Resources in the United States' featured a number of papers about climate impacts on urban water systems. A paper by O'Connor et al. (1999), for example, provided results of a survey of water providers in the US Susquehanna Basin. Findings of this study revealed that the size of operation is only weakly related, if at all, to vulnerability in the region's water systems and that vulnerability is not at all related to the number of different water systems available to the provider. Systems using surface water were found to be more vulnerable to climate impacts than those on groundwater, but systems using both sources were even more vulnerable than those using one or the other exclusively.

The CLIMAS sensitivity analysis discussed below avoids some of the pitfalls noted by Lins \& Stakhiv (1998) by employing scenarios that take into account future growth in demand, climatic conditions outside the parameters of water decision-making but not outside the realm of reasonable expectation of recurrence, and certain adaptation strategies. A survey of urban water providers is currently underway as an outgrowth of the sensitivity analysis. One component of the survey includes a slightly modified version of the questionnaire used in the Susquehanna study, allowing for cross-regional comparison. A companion institutional analysis, also in progress, addresses the ways in which existing rules and practices may facilitate or constrain effective response to the scenarios presented.

\section{STUDY SITES}

As noted earlier in this paper, the full CLIMAS urban water study included examination of the sensitivity of the water systems of the Phoenix, Tucson, and Santa Cruz AMAs, as well as of the Sierra Vista and Benson subwatersheds, to severe drought. Two of the urban areas included in the study were selected based on their size and consequent large water demand (Phoenix and Tucson are the 2 largest cities in Arizona). As noted earlier in this paper, Sierra Vista was selected because it has significant ongoing water resource issues associated with the presence of a large Army base, rapid urban growth, and strong pressures to protect a vital riparian area along the nearby San Pedro River. The results of the analyses of the Phoenix AMA, Tucson AMA, Santa Cruz AMA, and Sierra Vista subwatershed (see Fig. 1) are presented below.

5.1. Phoenix AMA. The Phoenix AMA encompasses by far the largest urban agglomeration in the State of Arizona. The AMA is home to some 2880000 people and hosts thriving electronics and service industries. By 2025, ADWR, using an AMA-level disaggregation of Arizona Department of Economic Security (DES) figures, estimates that the population will reach almost 
5 million (ADWR 1999a). Depending on the specific water service area, customers may receive water from 1 or more of the following sources: the Gila, Salt, Verde, Agua Fria Rivers, the CAP canal, and/or groundwater. Use of effluent as an additional water source remains quite low, although it constitutes a significant potential supply source for the AMA, and one that is projected to grow substantially.

5.2. Tucson AMA. The Tucson AMA, at about 840000 people, is the second largest urban area of the state. ADWR projections for the year 2025 show an anticipated population of 1266500 . The AMA continues to be almost entirely dependent on groundwater for its supplies, although the City holds one of the largest CAP allotments in the state. The CAP supply is considered crucial to the AMA's efforts to balance demand against renewable, rather than fossil, water supplies. Here, institutional issues (described later in this paper) currently prevent direct delivery of CAP water to customers. The AMA has been more successful than the Phoenix AMA in using its effluent supplies. The city lacks other legally developable water sources.

5.3. Sierra Vista subwatershed. Sierra Vista is a rapidly growing city of more than 39400 residents. It owes much of its vitality to multiplier effects generated by the adjacent Fort Huachuca Army Base and to its popularity as a retirement community. Situated close to one of the only unspoiled riparian areas in the state, the San Pedro River National Riparian Area, residents of the Sierra Vista subwatershed have for some years found themselves entangled in contests and litigation over what constitutes appropriate growth and concomitant water resource use. The city and the Fort have both initiated significant programs to manage local water resources more carefully and to cycle effluent into their water demand structures (CEC 1999). However, doubts remain that, even under normal climatic conditions, given current growth and development patterns and expectations, such measures will avert damage to the riparian zone.

\section{DESIGN AND METHODOLOGY}

Unlike most of the studies cited above, the CLIMAS urban water sensitivity analysis was constructed around a research question focused on natural climate variability rather than on anthropogenically induced climate change. Thus, the fundamental research question was, 'How would the most severe drought conditions in the historical record affect the water budget of each study area in the year 2025?' The analysis was carried out using spreadsheet-based calculations of changes in supply and demand in each area based on the historic minimum 1, 5, and $10 \mathrm{yr}$ winter precipitation levels within the climate division for that area. Baseline water supply and demand figures were obtained from ADWR for each location (ADWR 1991, $1999 a, b) ;$ then the numbers were adjusted to reflect the proportional reduction in winter precipitation for each scenario. For the Phoenix and Tucson AMAs, the 5 and 10 yr scenarios were run twice, once assuming CAP deliveries and once assuming a cutoff in CAP supplies for the entire drought period. Demand figures were adjusted based on population growth projected for the year 2025 in the respective AMA Third Management Plans (ADWR 1999a,b) (actual trends in that area over the past decade). ${ }^{1}$ A brief summary of the calculations and assumptions is provided below; for a more detailed discussion of the methodology, see Carter et al. (2000).

6.1. Determining renewable water supplies. Approximately 100 yr data on temperature and precipitation at the climate division level are available for all of the study areas (see Western Regional Climate Center, http://www.wrcc.dri.edu). Climate Division 7 was used for Sierra Vista and for the Tucson AMA, while Climate Division 4 was used for the Phoenix AMA. ${ }^{2}$ The data for the winter half of the year were examined to determine the most severe 1,5 , and $10 \mathrm{yr}$ droughts in the historical record (see Table 1). As noted earlier, the decision to use winter half-year precipitation, i.e. precipitation falling between November 1 and April 30, was based largely on the fact that most groundwater recharge is derived from mountain front recharge fed by winter precipitation (Sheppard et al. 1999). Furthermore, the majority of the streamflow captured behind dams on the Salt and Verde Rivers and used by Phoenix metropolitan area derives from winter precipitation. Also influential was research indicating that, while the Southwestern monsoon may account for significant rainfall in the summer, much of the water immediately evaporates (Sheppard et al. 1999). Significant levels of streambed recharge to local aquifers only occur during years when high summer precipitation and favorable antecedent moisture conditions coincide (Anderson et al. 1992). As winter precipitation data used for this analysis coincide with drought conditions lasting over both winter and summer seasons, it

\footnotetext{
${ }^{1}$ Notably, Sierra Vista has already exceeded DES projections for 2025

${ }^{2}$ Climate Division 4 was used for the Phoenix AMA in order to capture precipitation conditions in the Salt-Verde Rivers watershed, which is a key source of surface water supplies in that AMA. Climate Division 6, the other alternative, would have provided numbers within $10 \%$ of those produced using Climate Division 4, but would not have represented the higher-elevation watershed sufficiently
} 
Table 1. Climate data, by Climate Division, used in analysis. Note: $1 \mathrm{inch} \approx 2.54 \mathrm{~cm}$

\begin{tabular}{|lcccccc|}
\hline $\begin{array}{l}\text { Study } \\
\text { area }\end{array}$ & $\begin{array}{c}\text { Climate } \\
\text { division }\end{array}$ & $\begin{array}{c}\text { Mean annual } \\
\text { precipitation }\end{array}$ & $\begin{array}{c}\text { Mean winter precip- } \\
\text { itation (Nov-Apr) }\end{array}$ & $\begin{array}{c}\text { Driest } 1 \mathrm{yr} \\
\text { winter period }\end{array}$ & $\begin{array}{c}\text { Driest } 5 \text { yr winter } \\
\text { period (total) }\end{array}$ & $\begin{array}{c}\text { Driest 10 yr winter } \\
\text { period (total) }\end{array}$ \\
\hline $\begin{array}{l}\text { Phoenix } \\
\text { AMA }\end{array}$ & $\begin{array}{c}\text { East Central } \\
\text { (Div 4) }\end{array}$ & 19.00 inches & 10.21 inches & 1904 & $1900-1904$ & $1946-1955$ \\
& & & 1.18 inches & $\begin{array}{c}28.42 \text { inches } \\
74.66 \text { inches }\end{array}$ \\
Tucson & $\begin{array}{c}\text { Southeast } \\
\text { (Div 7) }\end{array}$ & 14.33 inches & 5.18 inches & $11.57 \%$ of mean & $55.7 \%$ of mean & $73.16 \%$ of mean \\
AMA/ & & & 0.6 inches & $1904-1904$ & $1947-1956$ \\
Sierra Vista & & & $11.58 \%$ of mean & $56.95 \%$ of mean & $73.94 \%$ of mean \\
\hline
\end{tabular}

was assumed that recharge from monsoonal rainfall would not contribute significantly to renewable water supplies in any of the study areas.

The analysis assumed linearity between precipitation and surface flows (see, for example, Nash \& Gleick 1991). Although the degree of linearity between rainfall and recharge (as well as surface flow) may depend upon antecedent moisture conditions and rainfall intensity, the precipitation amounts used were so low already that any alternative calculations would not have produced substantial changes in the proportion of surface flow or recharge.

The selection of the most severe 1, 5, and $10 \mathrm{yr}$ droughts in the historical record allows development of scenarios that could reasonably be expected to recur. For all study areas, the first decade of the 20th century produced the most severe 1 and $5 \mathrm{yr}$ droughts. The most severe 10 yr drought in all the study areas began in the late 1940s and extended into the mid-1950s. While arguments have been raised that the past is not a good indicator of the future, the alternative of using results from GCMs to run sensitivity analyses at the regional and finer-scale levels for the Southwest was rejected, primarily because none of the models have yet produced satisfactory results. Chief among the major concerns is that current GCMs do not satisfactorily reflect regional topography, ENSO influences, or the Southwestern monsoon. Further, the general consensus among the current climate modelers is that the Southwest will probably not experience any major overall climatic shift, although even greater variability at various time scales may be in store.

6.2. Determining demand. Baseline demand figures for the Phoenix and Tucson AMAs were derived from 1995 data (ADWR 1999a,b); 1990 data were the most recent available for the Sierra Vista subwatershed (ADWR 1991). Demand figures for 2025 were derived from ADWR and DES data (ADWR 1999a,b, DES 1999). Change in municipal demand produced by residential outdoor watering was calculated based on numbers derived from Woodard \& Horn (1988); changes in agricultural and riparian demand were calculated based on proportional changes in water needs (Carter et al.
2000). For purposes of the analysis, it was assumed that no special conservation measures would be introduced or enforced in response to the drought conditions. Although this would in fact be very likely to occur, especially during an extended drought period, the intent in this instance was to determine the maximum sensitivity of each study area. For all study areas, separate calculations were made using an alternative assumption of zero agricultural demand. This alternative was included in recognition of long-term trends in urbanizing areas of Arizona, where agriculture is rapidly being replaced by urban development.

6.3. Constructing the water budgets. Baseline water supply and demand data for the Phoenix and Tucson AMAs were derived from their respective Third Management Plan (ADWR 1999a,b). Due to unavailability of comparable data for 1995 at the time the analysis was done, 1990 baseline supply and demand data were used for Sierra Vista (ADWR 1991).

The year 2025 was chosen as the target date for the drought scenarios because this is the year specified in the Arizona GWMA by which the AMAs are expected to have achieved safe yield [A.R.S. § 45-562(A)]. Safe yield is defined as 'a groundwater management goal which attempts to achieve and thereafter maintain a long-term balance between the annual amount of groundwater withdrawn in an active management area and the annual amount of natural and artificial recharge in the active management area' [A.R.S. $§ 45-$ 561(12)]. Although the Sierra Vista area is not currently required to meet the safe-yield requirement, issues surrounding sustainability of water resources in the San Pedro River Basin suggest that drought scenarios based on 2025 population levels as well as on 1990 levels merit examination.

The 1, 5, and 10 yr drought scenarios for the Phoenix and Tucson AMAs were run against the baseline numbers, and against the projections developed by ADWR for the year 2025 (ADWR 1999a,b). For the Sierra Vista subwatershed, no projected water budgets were available, so projections were developed in-house, based on existing water supply/demand and projected increases in demand based on population growth fig- 
ures. Calculations involved straight-forward arithmetic operations.

For each water budget category, the proportional change from the 1995 and 2025 baseline numbers was calculated, based on the amount of precipitation produced during each drought period, and the new figure was entered into the appropriate spreadsheet cell. Total renewable supply and total demand were then calculated. To determine the impact of the scenario on the budget balance, total demand was subtracted from total renewable supply.

\section{FINDINGS AND DISCUSSION}

As shown in Table 2, sensitivity to climate is high in every study area in the single year and multi-year drought scenarios. For the Phoenix and Tucson AMAs, ability to achieve/maintain sustained yield by 2025, or to maintain safe yield, could be seriously undermined by extended drought. Although measures such as storage and banking of water for times of future shortage have been initiated, no structure exists for assuring that the water stored can actually be delivered where needed in such contexts. These and other impacts of the 1, 5 and 10 yr droughts on each study area are discussed in more detail below.

\subsection{Phoenix AMA}

The Phoenix AMA poses an interesting puzzle for water resource analysts in that it sprawls across a semiarid landscape, yet features numerous lakes, waterways, fountains and other water-intensive human con- structions. The AMA features singular problems with regard to water resources in that it not only encompasses areas entirely dependent upon limited groundwater supplies, but also features areas having access to multiple surface and groundwater sources. The Phoenix AMA also has waterlogged areas where managing the high water tables is more of an issue than conserving scarce water supplies (ADWR 1999a). Indian reservations within the AMA are anticipated to remain large agricultural water users, while nonIndian agriculture is expected to diminish under continued urbanization pressures. Some existing water rights settlements with Arizona tribes allow for the sale of water to urban areas, but how such arrangements would work out in a sustained drought remains to be tested.

Access to flows of the Salt and Verde River systems and to Colorado River supplies via CAP typically provides a buffer for much of the AMA. In part this occurs because movement of the jet stream northward often produces wet conditions in the upper Colorado watershed during years when the Salt-Verde watershed is experiencing dry conditions. Conversely, when wet conditions are favored in the Salt-Verde system, conditions may be relatively dry on the Upper Colorado. However, widespread drought conditions have been identified in the paleo record (Powell Consortium 1995, Sheppard et al. 1999) and could reasonably be expected to occur again. Loss of CAP flows and reductions in flows on the Salt-Verde system, as well as reduced groundwater recharge, would pose a serious challenge to water management in the AMA.

The CLIMAS sensitivity analysis indicates that the Phoenix AMA is quite sensitive to drought, and will become more vulnerable as its increasing population

Table 2. Percent overdraft of renewable supplies of 1, 5 and 10 yr drought scenarios. nc: not calculated; na: not applicable; parentheses indicate positive number (surplus, not overdraft)

\begin{tabular}{|c|c|c|c|c|c|c|c|c|}
\hline & $\begin{array}{c}1995 \\
\text { baseline }\end{array}$ & $\begin{array}{c}2025 \\
\text { baseline }\end{array}$ & $\begin{array}{c}2025 \\
\text { drought }\end{array}$ & $\begin{array}{c}2025 \\
\text { drought } \\
\text { w/o CAP }\end{array}$ & $\begin{array}{c}2025 \\
\text { drought + } \\
1995 \text { agric }\end{array}$ & $\begin{array}{c}2025 \text { drought } \\
+1995 \text { agric } \\
\text { w/o CAP }\end{array}$ & $\begin{array}{c}2025 \\
\text { drought } \\
\text { w/o agric }\end{array}$ & $\begin{array}{c}2025 \\
\text { w/o agric } \\
\text { w/o CAP }\end{array}$ \\
\hline \multicolumn{9}{|l|}{1 yr drought } \\
\hline Phoenix AMA & 20 & 24 & 68 & nc & 68 & $\mathrm{nc}$ & 43 & nc \\
\hline Tucson AMA & 70 & 15 & 36 & $\mathrm{nc}$ & 40 & $\mathrm{nc}$ & 24 & $\mathrm{nc}$ \\
\hline Sierra Vista & 25 & 32 & 76 & nc & nc & nc & 82 & nc \\
\hline \multicolumn{9}{|l|}{5 yr drought } \\
\hline Phoenix AMA & 20 & 24 & 47 & 67 & 47 & 68 & 6 & 64 \\
\hline Tucson AMA & 70 & 15 & 28 & 78 & 33 & 80 & 14 & 74 \\
\hline Sierra Vista & 25 & 32 & 56 & na & na & na & 59 & na \\
\hline \multicolumn{9}{|l|}{$10 \mathrm{yr}$ drought } \\
\hline Phoenix AMA & 20 & 24 & 39 & 59 & 38 & 59 & (8) & 27 \\
\hline Tucson AMA & 70 & 15 & 25 & 75 & 30 & 69 & 11 & 71 \\
\hline Sierra Vista & 25 & 32 & 47 & na & na & na & 50 & na \\
\hline
\end{tabular}


exerts greater pressure on water supplies. In 1995, $20 \%$ of the AMA's water demand had to be met by non-renewable supplies; by 2025, this proportion is expected to increase to $24 \%$, or 543254 af of groundwater mining annually under mean climatic conditions. Under historic $1 \mathrm{yr}$ drought conditions, the AMA could experience a renewable supply deficit of $68 \%$ under both projected agricultural demand and if agriculture remains at 1995 levels (as opposed to the slight increase in demand that has been projected). Even if agricultural demand were eliminated entirely, drought conditions would still force the AMA to rely on nonrenewable supplies to meet $43 \%$ of its needs.

It is important to note here that, in the case of the Phoenix AMA, surface water is a major input to agriculture, and thus eliminating agriculture frees up a considerable amount of water for other uses. We made the assumption that the $1 \mathrm{yr}$ drought, which produced a deficit of approximately $88 \%$, would result in the same magnitude of decrease in surface water availability. We recognize, however, that storage capacity on the Salt-Verde River system would probably buffer this impact, making the assumption of such a drastic reduction in surface water available to meet demand an unlikely, though not unthinkable, scenario. Interestingly, we found that eliminating agriculture has a markedly greater impact on freeing up water for alternative uses in the 5 and $10 \mathrm{yr}$ droughts than in the $1 \mathrm{yr}$ drought. This is because 5 and $10 \mathrm{yr}$ droughts produced precipitation deficits of only about half the normal amount, particularly since we assumed that surface water availability would decrease by the same proportion over the entire period. Thus considerably more water could be made available for other uses than was the case in the 1 yr drought.

It must also be noted that the proportional impact of eliminating agriculture during drought periods was much greater in the Phoenix AMA, within and across the 3 scenarios, than it was in the Tucson AMA. Indeed, the variation in impacts in the Tucson AMA amounted to less than $15 \%$ with regard to including versus excluding agricultural demand, and between the 1,5 , and 10 yr scenarios. The reason for this is that the Tucson AMA has no significant natural surface water resources in its water budget and has less agricultural water use overall. The result is that drought impacts are restricted to groundwater and CAP water availability, and to elimination of a smaller proportion of total demand. Thus, the change in renewable supply and consequent impact of eliminating agriculture occurs within a substantially smaller range of variation than is the case in the Phoenix AMA.

Findings of the sensitivity analysis further indicated that a smaller annual average imbalance between demand and renewable supply would occur in the
Phoenix AMA under the 5 and 10 yr scenarios than in the 1 yr scenario. Nevertheless, the cumulative effects over the entire course of the drought would certainly pose significant challenges for water management. Any cutoff in CAP water availability would further exacerbate the problem. In this light, an important unanswered question is whether existing Arizona water law would be sufficient to address the impacts. The language of the GWMA does not specify what consequences might arise from failure to maintain safe yield under a multi-year drought, and, as noted above, it is unclear how water stored and banked would be allocated among competing interests in times of shortage.

As indicated in Table 2, the 5 yr drought scenario indicates that the proportion of demand not met by renewable supplies would range from $47 \%$, under projected 2025 baseline conditions with full access to CAP, to $68 \%$ if CAP were cut off while agricultural demand were sustained at 1995 levels. By contrast, under the 10 yr drought scenario, if agriculture demand and CAP were both eliminated for the entire period, the Phoenix AMA could still see a $27 \%$ deficit of supply versus demand. Assuming agricultural demand at 1995 levels and loss of CAP water under drought conditions, nonrenewable supplies would have to be used to reach $59 \%$ of total demand.

Under the worst-case scenarios (especially the $5 \mathrm{yr}$ drought with 1995 agricultural demand but no CAP supplies), it is unlikely that accustomed lifestyles and livelihoods could be maintained at non-drought levels. ADWR (1999a) data and preliminary results from our survey of water providers in the study areas suggest that some providers and customers would be significantly more vulnerable than others to severe drought, often because their ability to adapt to changing conditions is institutionally constrained. For example, regulations governing small private water companies present a serious constraint to their ability to recover costs by raising customer prices. While they may be able to obtain permission from their regulatory agency, the Arizona Corporation Commission (ACC) to cover higher costs associated with operating their system, they may not raise prices to cover costs associated with efforts to increase water conservation behavior among their customers.

\subsection{Tucson AMA}

The Tucson AMA is almost as sensitive as the Phoenix AMA to severe drought conditions. Even under mean climatic conditions, total water demand in the AMA exceeded renewable supplies by $70 \%$. This amount of overdraft is expected to be reduced to $15 \%$, 
or 49500 af annually by 2025, despite population growth, due to greater utilization of CAP supplies and a projected $29 \%$ decrease in agricultural water demand. Under the historically worst 1 yr drought, and assuming current conservation measures, demand would exceed renewable supply by $36 \%$, or 114806 af. Maintaining agriculture at 1995 levels could force the AMA to rely on non-renewable supplies to meet $40 \%$ of its demand, while totally eliminating agriculture still results in a $24 \%$ deficit in renewable supplies versus demand. Under the 5 yr drought scenario, demand could exceed renewable supply by 28 to $80 \%$, depending upon whether or not CAP supplies were available and whether or not agriculture were to be eliminated. The 10 yr drought scenario results in demand exceeding renewable supply by 11 to $30 \%$ with normal CAP supplies, in a 71 to $75 \%$ imbalance if CAP water were cut off.

The nature of Tucson AMA's sensitivity to drought can be explained in part by the AMA's lack of alternative potable sources other than groundwater and CAP. For non-potable uses, effluent would be available. However, the customer base for effluent is quite limited, and many of the largest potential users (golf courses) already use effluent for turf irrigation. Access to the delivery system also limits effluent use (ADWR 1999b). It is highly unlikely that, except possibly for the $10 \mathrm{yr}$ drought, the climatic conditions used in this analysis would be of sufficient duration to prompt construction of additional effluent delivery infrastructure. Thus, stringent conservation measures, drawing down stored and banked water, and mining of fossil groundwater would probably all be required to reconcile supply and demand.

In the Tucson AMA, institutional arrangements governing water management, rather than precipitation fluctuations per se, constitute a major barrier to coping sufficiently and effectively with drought-induced water scarcity. Choices would have to be made about whether to intensify pumping of fossil groundwater, recover recharged CAP or effluent water, make arrangements to obtain water from other rights holders, such as farmers, and/or institute very stringent conservation measures.

Also important is the limited capacity of the primary urban water provider, Tucson Water, to meet high rates of demand when even modest declines in precipitation

\footnotetext{
${ }^{3}$ In Fall 1999, Tucson voters rejected an initiative to further strengthen the Water Consumer Protection Act. The vote indicates that consumer resistance to use of CAP water is diminishing; however, direct delivery of exclusively CAP water is not expected to occur in the near future. Tucson Water is currently delivering a blend of recharged CAP and natural groundwater to many of its customers
}

are experienced. For example, in June 1999, Tucson Water announced through the local newspapers that strict conservation rules would be invoked and enforced if water demand did not abate (Arizona Daily Star 1999). The onset of the summer monsoon season during the first week of July averted the need to implement strong measures, but the problem will certainly arise again, for the city continues to lack sufficient reservoir storage capacity to withstand even very short-term dry conditions.

Further constraints are posed by the Water Consumer Protection Act, a local voter-approved initiative that requires the city to either recharge its CAP water (injection wells are banned) or arrange for CAP water use by agriculturalists, mines, and other concerns in exchange for the right to use their groundwater. Under this law, the Tucson AMA remains dependent upon groundwater for its supplies, since pumping recharged CAP water constitutes the primary renewable supply for potable uses. ${ }^{3}$ The aquifers underlying the AMA are very large, but most of the water in the deposits is several thousand years old. Mining of this fossil water is deemed to be unsustainable over the long term due to the problems posed by ground subsidence, fissuring, and declining quality as deeper deposits are tapped. The only way the Tucson AMA can even approach safe-yield, as defined under the GWMA (see above), is to augment its supplies. The area has done so primarily by contracting for large amounts of CAP water, and developing a separate effluent system and effluent utilization program. Facilities to recharge large amounts of CAP water have not yet been operationalized (significant questions remain about where and how such large-scale recharge could be accomplished), and effluent use remains limited, primarily directed toward some-but notably not all-of the golf courses in the AMA. Ironically, one of the biggest challenges the Tucson AMA currently faces is how to make use of all of its 'renewable' water supplies (i.e. CAP and effluent, plus the renewable fraction of water entering local aquifers). Given continued growth in water demand in California and Nevada, Arizona and its local jurisdictions must continue to work hard to ensure that its allocation under the Colorado Compact is protected.

Under the drought scenarios used in the CLIMAS sensitivity analysis and assuming no substantial progress in developing recharge and recovery facilities and institutional mechanisms, Tucson would experience large impacts on its groundwater supplies. If CAP supplies were cut off, the impacts would be even more severe. The 1 yr drought could probably be managed under existing infrastructural and institutional arrangements; however, under these arrangements, the 5 and $10 \mathrm{yr}$ droughts would severely strain the system. 


\subsection{Sierra Vista subwatershed}

In the Sierra Vista area, water scarcity at the levels calculated in the sensitivity analysis would pose serious challenges for water and land managers. If the worst 1 yr drought on record occurred under projected 2025 demand levels, the imbalance between renewable supply and demand would be 76 to $82 \%$. Under the 5 and $10 \mathrm{yr}$ scenarios, the area would experience significantly lower impacts, although even under the best circumstances drought would occasion an imbalance between renewable supply and demand in the range of 47 to $59 \%$. As indicated in Table 2, overdraft increases when agriculture is eliminated, which may seem counterintuitive. However, this result is based on the assumption that elimination of agriculture would eliminate return flows and incidental recharge, which would otherwise be reflected on the supply side of the water budget. While Sierra Vista is not under the more stringent regulatory requirements imposed by the GWMA on the Phoenix and Tucson AMAs, it is highly unlikely that overdrafting of aquifers would be sustained at these levels under existing political relations at the local, regional, state, and national level.

In the absence of alternative sources of water, very strict conservation measures constitute the only viable alternative to balancing ecosystem needs with urban demand. This is already a sensitive issue, and one that has stimulated a considerable amount of research in areas such as evapotranspiration rates of riparian vegetation, surface and groundwater recharge, and interactions between climate and watershed dynamics more generally. The issues of most concern are whether the cone of depression under the urban area does (or will) capture water that would otherwise flow in the San Pedro River, and how to augment existing supplies. Although some consideration was given to extending the CAP system to the area, it was soon recognized that the cost would be prohibitive. As currently written, Arizona water law also prohibits transfer of water from one basin to another. Suggestions continue to be made that water be transferred from the Douglas basin to the east of the San Pedro watershed (CEC 1999); however, Douglas residents have continued to voice strong opposition allowing even for the notion to be voiced. Undoubtedly, any attempt to change the current law would be strongly resisted not only by Douglas-area residents, but by residents in other parts of the state. The most viable options at present, and ones that the community is now actively pursuing, are to enhance water conservation and to capture and reuse effluent flows. The question that remains unanswered is whether these measures will suffice to address local needs under extended drought conditions such as those specified in the sensitivity analysis scenarios.

\section{COMPARISON OF DIFFERENCES IN SENSITIVITY AMONG THE STUDY AREAS}

Not surprisingly, all of the study areas share a high sensitivity to severe drought. Phoenix may be best positioned to cope with drought impacts, in that it has greater access to surface water sources, and has waterlogged areas that could be tapped to bolster supplies in watershort areas. Further, to date, water banking is much further advanced in Phoenix than in Tucson while this alternative is not available in the Sierra Vista area.

So long as CAP water remains available, Tucson remains relatively well buffered against even severe droughts of 5 to $10 \mathrm{yr}$ duration, while Phoenix would likely see a substantial increase in groundwater overdraft. Sierra Vista is by far the most seriously affected area, however, in all the drought scenarios tested, due to lack of substantial surface water or alternative groundwater sources.

Eliminating all agricultural demand produces significant reductions in the Phoenix and Tucson AMAs, with Phoenix showing only a $6 \%$ overdraft in the $5 \mathrm{yr}$ drought scenario and an $8 \%$ surplus in the $10 \mathrm{yr}$ drought. By contrast, eliminating agriculture in Sierra Vista actually increases the deficit, due to the loss of return flows that could benefit other uses, such as for riparian vegetation along the San Pedro River. Eliminating CAP water over the 5 and 10 yr drought scenarios in the Phoenix and Tucson AMAs, not surprisingly, produces the highest deficits, rising as high as 75 to $80 \%$ in the Tucson AMA and 59 to $68 \%$ in the Phoenix AMA. The higher Tucson deficit reflects the lack of any other significant surface water sources.

\section{CONCLUSIONS}

The sensitivity analysis discussed in this paper suggests that, even though substantial progress has been made in buffering communities against the impacts of drought, growth and development trends may be outpacing the ability of water managers to meet demand under conditions of severe drought. This is particularly the case if a deep $10 \mathrm{yr}$ drought, such as that which occurred in the 1950s, were to happen in the next 25 to 30 yr. The Phoenix and Tucson AMAs already recognize that achieving safe yield by 2025 as mandated by the GWMA is probably not possible (see Norton 1999). Factoring in the possibility of such a drought further reduces the likelihood of achieving - and remaining in-compliance with this requirement.

Institutional arrangements in the AMAs, such as water banking, recharge of surplus CAP water, and expansion of effluent use, provide an important buffer against short-term drought (5 yr or less). However, 
deep, sustained drought conditions could seriously stress capacity to support demand at even close to 'normal' levels. Addressing these problems by pumping more groundwater in quantities sufficient to redress drought-related water budget imbalances may not be a viable solution, unless the public is willing to support costly infrastructure enhancements and to accept the potential consequences of intensified pumpage. In riparian areas, intensive pumping over even short periods would likely destroy delicate and increasingly rare ecosystems. Over longer periods, intensive groundwater pumping could pose threats in the form of land subsidence, diminished water quality, and possibly even reduced reliability of delivery.

Based on the sensitivity analyses for the 3 study areas, strict enforcement of stringent conservation rules could reduce some of the need for expensive supply augmentation measures and could contribute to reducing stress on fragile ecosystems. Maintaining strict conservation rules over long periods of time (such as a 10 yr drought) could prove problematical, however, particularly when such measures threaten important assets such as home values. Anomalous wet periods within a longer drought sequence, as happened in the 1950s, could also pose a challenging conservation enforcement as residents-believing that the drought is over-revert to previous water utilization patterns.

The extent to which seasonal to interannual forecasts of drought onset or continuation would facilitate management of water resources remains to be evaluated, for no drought of the magnitude of that experienced in the 1950s has yet occurred. If, as some suggest (see Sheppard et al. 1999), the Pacific Decadal Oscillation pattern is moving into a new dry phase, we may yet see recurrence of a severe multi-year drought.

The second phase of the CLIMAS urban water study, currently underway, involves an examination of the vulnerability of the urban water sector to climate. The methodology includes a survey of providers and an analysis of the institutional framework within which water management decisions are made at the local, state, and national level. Preliminary results indicate that climate impacts are likely to be experienced differentially even within each study area, based on the size of the water provider, types of water available, nature of infrastructure, nature of customer base, physical characteristics of the water source area, and other factors. This suggests that considerable flexibility should be built into any policies or response plans devised to cope either proactively or reactively with drought stresses. Further, consideration should be given to assuring that climate information and forecasts provided to water managers addresses, to the extent possible, their specific concerns and needs, and that decision makers are adequately informed about how to use available climate and hydrologic information and forecasts.

Acknowledgements. The CLIMAS urban water study was funded by the National Oceanic and Atmospheric Administration under Cooperative Agreement \#NA87GP0061. Conclusions presented here are entirely those of the authors.

\section{LITERATURE CITED}

ADWR (1991) Hydrographic survey report for the San Pedro watershed, Vol 1, General Assessment. In: Re the General Adjudication of the Gila River System. Arizona Department of Water Resources, Phoenix

ADWR (1999a) Third Management Plan, Phoenix Active Management Area. Arizona Department of Water Resources, Phoenix

ADWR (1999b) Third Management Plan, Tucson Active Management Area. Arizona Department of Water Resources, Phoenix

ADWR (1999c) Third Management Plan, Santa Cruz Active Management Area. Arizona Department of Water Resources, Phoenix

Anderson TW, Freethey GW, Tucci P (1992) Geohydrology and water resources of alluvial basins in South-Central Arizona and parts of adjacent states. US Geological Survey professional paper 1406-B. US Government Printing Office, Washington, DC

Arizona Daily Star (1999) Ultra-dry forecast heightens calls to 'Beat the Peak.' May 23, p 1A

Boland JJ (1997) Assessing urban water use and the role of water conservation measures under climate uncertainty. Clim Change 37:157-176

Carter RH, Tschakert P, Morehouse BJ (2000) Assessing the sensitivity of the Southwest's urban water sector to climate variability. Institute for the Study of Planet Earth, The University of Arizona, Tucson

CEC (1999) Ribbon of life: an agenda for preserving transboundary migratory bird habitat on the Upper San Pedro River. Commission for Environmental Cooperation, Montreal

DES (1999) Arizona Department of Economic Security population projections. Department of Economic Security, Phoenix, AZ; available at http://www.de.state.az.us/links/ economic/webpage/popweb

Frederick KD (1995) America's water supply: status and prospects for the future. Consequences Nat Implicat Environ Change 1(1):14-23

Frederick KD, Major DC (1997) Climate change and water resources. Clim Change 37:7-23

Gleick PH, Nash L (1991) The societal and environmental costs of the continuing California drought. Pacific Institute Report, Pacific Institute for Studies in Development, Environment, and Security, Oakland, CA

Harding BL, Sangoyomi TB, Payton EA (1995) Impacts of a severe sustained drought on Colorado River water resources. In: Powell Consortium (ed) Severe sustained drought, managing the Colorado River system in times of water shortage, Issue No. 1. Papers reprinted from Water Resour Bull 31(5), October 1995, by the Water Resources Research Center, The University of Arizona, Tucson, p 815-824

IPCC (1996) Climate change 1995: impacts, adaptations, and mitigation of climate change, scientific-technical analyses. 
Contribution of Working Group II to the Second Assessment Report of the Intergovernmental Panel on Climate Change. Cambridge University Press, Cambridge

Lins HF, Stakhiv EZ (1998) Managing the nation's water in a changing climate. J Am Wat Res Assoc 34(6):1255-1264

Maddock TS, Hines WG (1995) Meeting future public water supply needs: a Southwest perspective. Water Resour Bull 31:319-325

Merideth R, Liverman D, Bales R, Patterson M (1998) Climate variability and change in the southwest: impacts, information needs, and issues for policymaking. Final report of the Southwest Regional Climate Change Symposium and Workshop, September 3-5, 1997, Tucson, AZ. Udall Center for Studies in Public Policy, University of Arizona, Tucson

Nash L (1993) Environment and drought in California, 1987-1992: impacts and implications for aquatic and riparian resources. Pacific Institute for Studies in Development, Environment and Security, Oakland, CA

Nash LL, Gleick PH (1991) Sensitivity of streamflow in the Colorado Basin to climatic changes. J Hydrol 125:221-241

Nash LL, Gleick PH (1993) The Colorado River Basin and climatic change: the sensitivity of streamflow and water supply to variations in temperature and precipitation. EPA230-R-93-009, US Environmental Protection Agency, Washington, DC

Norton DR (1999) Performance audit, Arizona Department of Water Resources. Report to the Arizona Legislature. State of Arizona Office of the Auditor General, Report No. 99-8, April 1999

O'Connor RE, Yarnal B, Neff R, Bord R, Wiefek N, Reenock C, Shudak R, Jocoy CL, Pascale P, Knight CG (1999) Weather

Submitted: May 5, 2000; Accepted: January 8, 2001 and climate extremes, climate change, and planning: views of community water system managers in Pennsylvania's Susquehanna River Basin. J Am Wat Res Assoc 35(6): 1411-1419

Powell Consortium (1995) Severe sustained drought: managing the Colorado River in times of water shortage, Issue No. 1. Papers reprinted from Water Resour Bull 31(5), October 1995, by the Water Resources Research Center, The University of Arizona, Tucson

Revelle RR, Waggoner PE (1983) Effects of a carbon dioxideinduced climatic change on water resources in the western United States. In: Changing climate: report of the Carbon Dioxide Assessment Committee. National Academy of Sciences, National Academy Press, Washington, DC, p 419-432

Schwarz HE, Dillard LA (1990) Urban water. In: Waggoner PE (ed) Climate change and U.S. water resources. Wiley, New York, p 341-366

Sheppard PR, Comrie AC, Packin GD, Angersbach K, Hughes MK (1999) The climate of the Southwest. CLIMAS report series CL 1-99. Institute for the Study of Planet Earth, The University of Arizona, Tucson, AZ

Stockton CW, Boggess WR (1979) Geohydrological implications of climate change on water resource development. US Army Coastal Engineering Research Center, Fort Belvoir, VA

Woodard GC, Horn C (1988) Effects of weather and climate on municipal water demand in Arizona. Report prepared for the Arizona Department of Water Resources and Tucson Water, Division of Economic and Business Research, College of Business and Public Administration, University of Arizona, Tucson

Proofs received from author(s): July 10, 2001 